\title{
Fabrication and characterization of cane fiber reinforced unsaturated polyester resin composites
}

\author{
M. H. A. Begum* and N. I. Tanvir \\ Industrial Physics Division, BCSIR Laboratories, Dhaka, Bangladesh
}

Received: 31 December 2017

Revised: 06 December 2018

Accepted: 06 May 2019

DOI: $10.3329 /$ bjsir.v54i3.42677

\begin{abstract}
Cane fiber of the generas Acoruscalamus, Daemonorops Draco, Daemonoropsmollis climbing palms of tropical Asia, belonging to the family palmae (palm family) and unsaturated polyester resin were used for the preparation of composites. Cane fiber was modified with $5 \%, 10 \%, 15 \% \mathrm{NaOH}$ solution. Various physical and mechanical properties of the composite for different orientations of fiber were measured. The physical properties i.e. water absorption of treated fiber reinforced composites is lower. But the moisture content of cane fiber decreases with higher concentration of alkali solution used for treatment. The ultimate tensile strength (UTS) is higher for treated fiber reinforced composites than the raw fiber reinforced composites for any types of orientations of fibers and the tensile strain of treated fiber reinforced composites is lower than the raw fiber reinforced composites. The UTS value for treated cane fiber composites increases with increasing weight percentage of fiber than the raw fiber reinforced composite.
\end{abstract}

Keywords: Cane fiber, Composites, $\mathrm{NaOH}$ solution, Orientation of fiber, Reinforced, Treated fiber.

\section{Introduction}

The term composite means a type of solid material consists of two or more dissimilar separate materials (Richardson, 1987; Mathur 2006). But in modern materials engineering, the term usually refers to a matrix material that is reinforced with fibers. Metals and plastics are not considered composites although they have a lot of fillers and impurities. Only if a significant change in the properties is achieved than the material considered a composite. Composite materials have used vastly in many fields for their better thermo-mechanical properties (Kafi et al., 2006; Khan et al., 2010; Hattum et al.,2011). Most composites have at least two constituent materials: a binder or matrix and a dispersed phase for reinforcement. The reinforcement is usually much stronger and stiffer than the matrix and gives the composite good properties. Reinforcements basically come in three forms: particulate, discontinuous fiber, and continuous fiber (Callister, 2000). Renewable fibers are often considered for low cost and high production rates compromising low performance. These fibers have many properties that would be an advantage in other fields, such as light weight, high specific strength compared to glass and carbon and low energy requirements for processing. Natural fibers can be substituted for glass and carbon fiber in polymer composites. The art of making composites is restricted mainly to synthetic polymer and synthetic reinforcing fibers like glass, carbon and nylon. The potentiality of natural fiber-based composites using cellulose, wood, jute, kenaf, hemp, sisal, rice husk, wheat, barley, oats, grass, reeds, rye, bamboo, banana fiber, pineapple, cane, coir, etc., as reinforcing fiber in a thermosetting resin matrix has received considerable attention among scientists all over the world for their excellent specific properties (Jawaid, et al., 2011; Nayak et al., 2009; Joseph and Thomes, 2008). Some of them have already been used as industrial products. Composites based on thermoplastic resins are now becoming popular due to their processing advantages (Wiley J and Sons, 1998 ). Cellulose fibers are used in the manufacture of paper and cloth. Animal fibers generally comprise proteins; examples include silk, wool, angora, mohair, alpaca etc. Cane fiber comes from the category of bast fiber or skin fiber. These fibers have higher tensile strength than other fibers. Therefore, these fibers are used for durable yarn, fabric,

*Corresponding author e-mail: hosneyara@gmail.com 
packaging and paper production. Resin is an important constituent in composites (Akter et al., 2013). Two classes of resins are the thermoplastics and thermo sets. A thermoplastic resin remains a solid at room temperature. It melts when heated and solidifies when cooled. The long chain polymers do not form strong covalent bond. That is why they do not harden permanently and are undesirable for structural application. On the other hand, a thermoset resin will harden permanently by irreversible cross-linking at elevated temperatures. This characteristic makes the thermo set resin composites very desirable for structural applications. The most common resins used in composites are the unsaturated polyesters, epoxies and vinyl esters; the least common ones are the polyurethanes and phenolics. The most important composites are those in which the dispersed phase is in the form of a fiber. Design goals of fiber-reinforced composites often include high strength and /or stiffness on weight basis. These characteristics are expressed in terms of specific strength and specific modulus parameters, which correspond respectively, to the ratios of tensile strength to specific gravity and modulus of elasticity to specific gravity (William, et al. 2000). In this study, we investigate the physical and mechanical properties of cane fiber reinforced polyester resin composite. Composites are made with the raw fibers and $\mathrm{NaOH}$ treated fibers at different orientation. The physical and mechanical properties of those composites were investigated.

\section{Materials and methods}

The raw materials used for preparing the samples were unsaturated polyester resin (UPR), hardener (methyl ethyl ketone peroxide "MEKP") and cane fiber. About 500 gm cane fiber are collected from the skin or bust surrounding the stem of the genera calamus, daemonorops and korthasia climbing palms of sylhet (Bangladesh) belonging to the family palmae (palm family). Unsaturated polyester resin and MEKP hardener were collected from the local market.

Raw cane fiber was treated with $\mathrm{NaOH}$ solution to extract impurities from cane fibers such as hemi-cellulose, lignin, aromatic acids, ester etc. which might weaken the adhesion between fibers and matrix. Cane fibers were immersed in $\mathrm{NaOH}$ solution of volume $\%$ of $15 \%$ and the treatment time was 24 hours which was the optimum condition among the treated fibers for volume $\%$ of $5 \%, 10 \%$ and $15 \%$ for $30 \mathrm{~min}$, 1 hour, 24 hours, 48 hours and 96 hours at room temperature. The fibers were washed with distilled water to neutralize the $\mathrm{NaOH}$ solution for 3 hours under flowing water. Then they were dried at $80^{\circ} \mathrm{C}$ for 24 hours in an oven and cut into 6 inch and 8 inch long pieces.

Cane fibers were orientated in different forms for preparations of different types of samples. At first the gap between two fibers was equal to the width of a single fiber, then the gap was equal to the width of two fibers and lastly samples were prepared without any gap between the fibers. The directions of fibers were longitudinal and vertical for a sample.

At first a bottom part of mild steel or stainless steel was taken according to the size of the fiber sheet, a melot paper was placed on dried bottom part. Then a mixture of resin and hardener was spread evenly on the melot paper.

After this one sheet of cane was placed on the open mold and covered with melot paper. Another metal sheet similar to that of the bottom one was placed on the melot paper and the total set up was given on the UTM(Model: FS300 KN, Company: Testometric, Origin: England) to give pressure so that the resin can evenly distributed.

The prepared samples were allowed to cure in this stage under approximate $10 \mathrm{KN} /(25 \mathrm{~cm} \times 25 \mathrm{~cm})$ pressure in UTM at room temperature for 24 hours. After applying the required pressureandallowing particular time, the sample (prepared by the abovementioned method) was collected from the UTM machine.

\section{Results and discussion}

The effect of alkali treatment of cane fiber is illustrated in this section, under physical properties of fiber, mechanical properties of fiber andmechanical properties of composite.

\section{Physical properties of fiber}

\section{Water absorption}

Figs. 1a-d view that water absorption (g) is lower for single gap oriented raw fiber reinforced composite among the raw fiber reinforced composites. For without gap orientation water absorption is lower for treated fiber reinforced composite. Fig. also show that water absorption increases with the increase of fiber content, as it is a diffusion phenomenon. Water absorption is responsible only for fiber and higher the fiber addition higher will be the water intake. Alkali treatment of fiber are expected toblock the hydroxyl groups of natural fiber thus making the fibers more hydrophobic that's why water absorption of alkali treated fiber reinforced composite is lower than the raw fiber reinforced composite. 


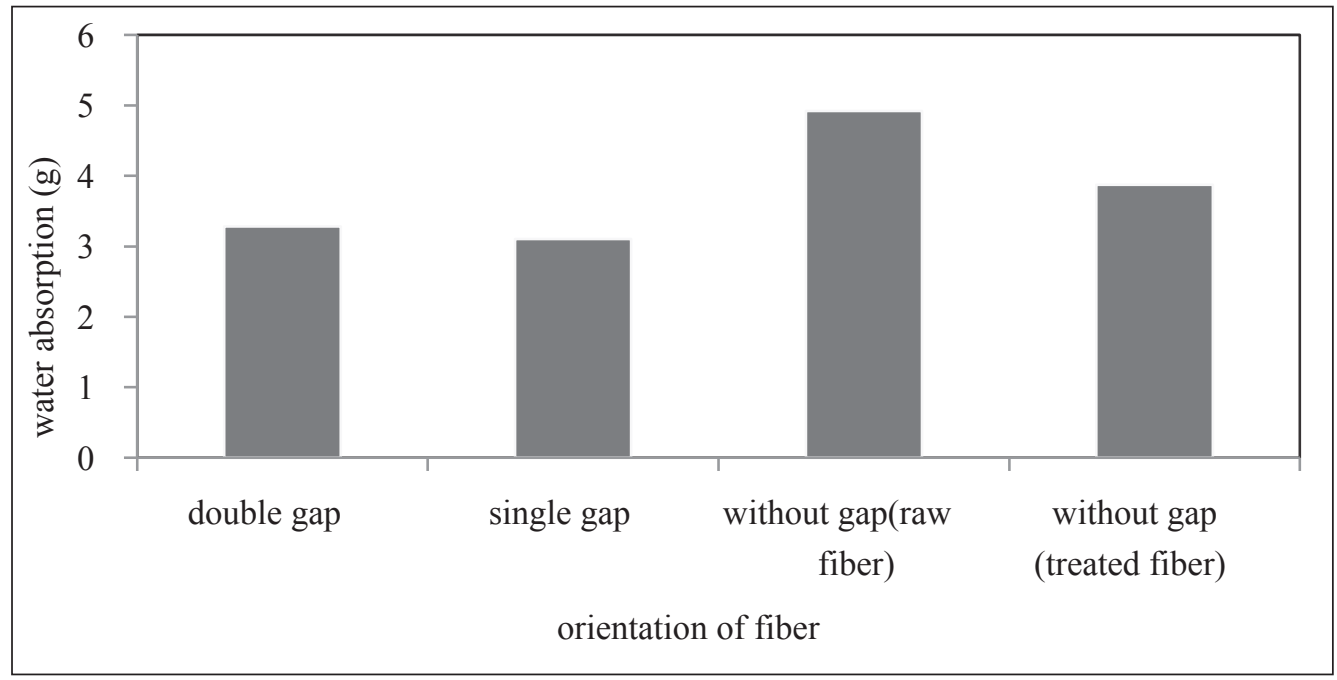

Fig. 1a. Water absorption at different orientations of fiber

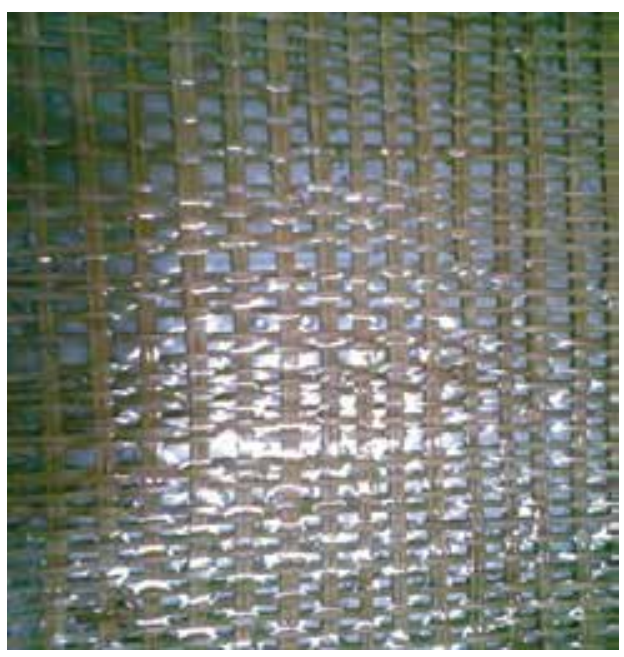

Fig. 1b: Single gap orientation of raw fibers, longitudinal and transverse

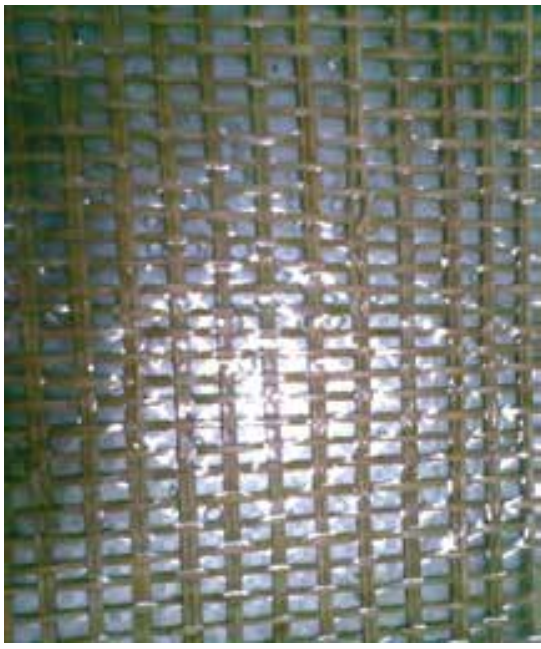

Fig. 1c:Double gap orientation of raw fibers longitudinal and transverse

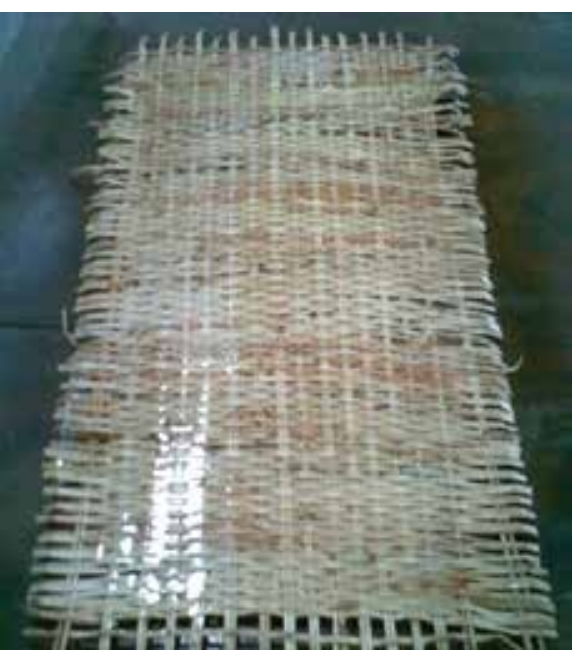

Fig. 1d:Without gap orientation of raw fibers longitudinal and transverse

\section{Mechanical properties of fiber}

\section{Fiber strength}

Fig. 2 shows that for $5 \%, 10 \%$ and $15 \% \mathrm{NaOH}$ treated cane fibers the ultimate tensile strength (UTM) increases linearly up to 24 hours then decreases linearly up to 96 hours. From the above graph we see that the ultimate tensile strength is higher for 24 hours treated fibers.

Alkali treatment can remove natural and artificial impurities and produce a rough surface topography of the fiber. In addition, alkali treatment leads to fiber fragmentation, i.e. breaking down the fiber bundle into smaller fibers. This treatment increases the effective surface area available for wetting. Hence increasing the fiber aspect ratio caused better interfacialpropertiesof fiber as well as increased the mechanical properties.

\section{Fiber strain}

Fig. 3 shows that the tensile strain (\%) for $5 \% \mathrm{NaOH}$ treated fiber is lower at 30 minutes and higher for 24 hours, for $10 \%$ $\mathrm{NaOH}$ treated fiber the tensile strain (\%) is lower at 48 hours 


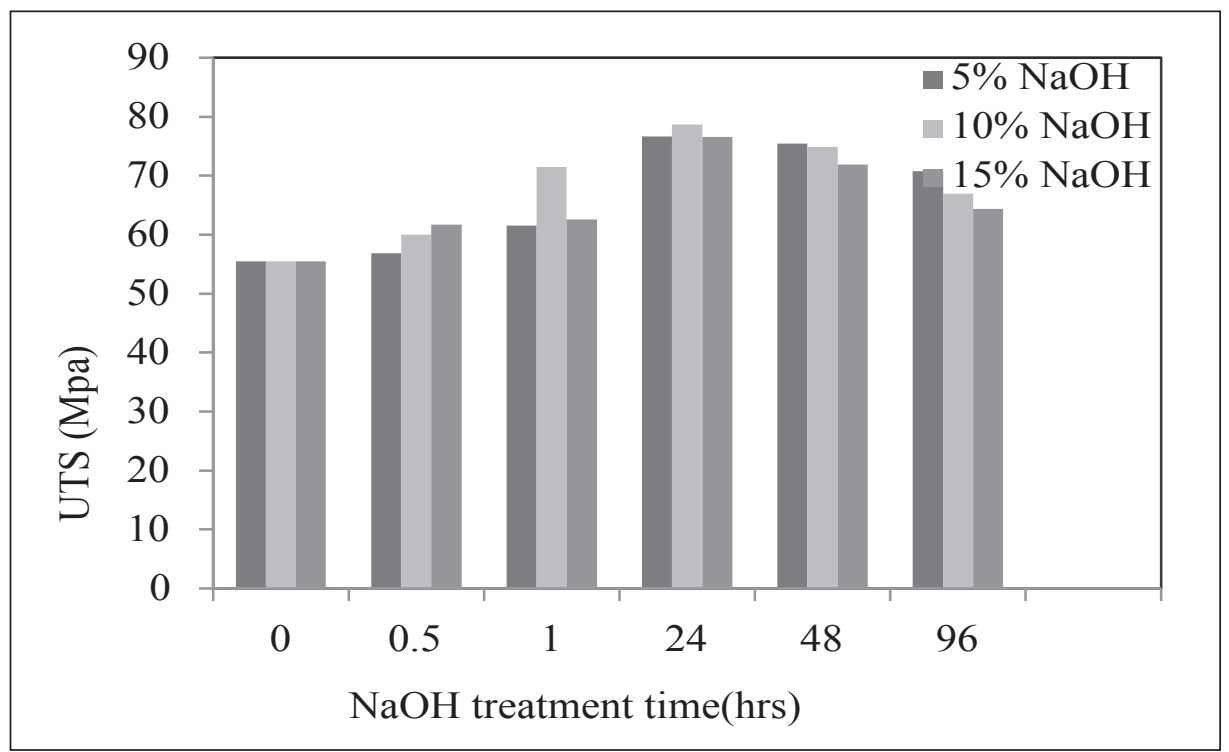

Fig. 2. Ultimate tensile strength (UTM) of $\mathrm{NaOH}$ treated cane fiber at different times

and higher at 1 hour and for $15 \% \mathrm{NaOH}$ treated fiber tensile strain $(\%)$ is lower at 48 hours and higher for raw fibers.

\section{Moisture content of fiber}

Fig. 4 shows that moisture content is higher for raw fibers than the treated fibers. For $5 \%, 10 \%, 15 \% \mathrm{NaOH}$ treated fibers moisture content is lower at 48 hours, $30 \mathrm{~min}$. and 48 hours respectively.Raw fiber contains huge amount of materials like lignin, hemicellulose, pectin etc. which have high hydrophilic polar group through which they can easily form hydrogen bond with moisture and hence absorb them. So, the moisture content of fibers is higher. By means of alkali treatment, these polar substances can be dissolved and removed. With enhancement of alkali concentration, the rate of moisture absorption is reduced.

\section{Optimum condition of fiber treatment}

From the above discussions, the optimum condition can be found. The ultimate tensile strength is higher at 24 hours for $5 \%, 10 \%$ and $15 \% \mathrm{NaOH}$ treated fibers but for $5 \%$ and $15 \%$

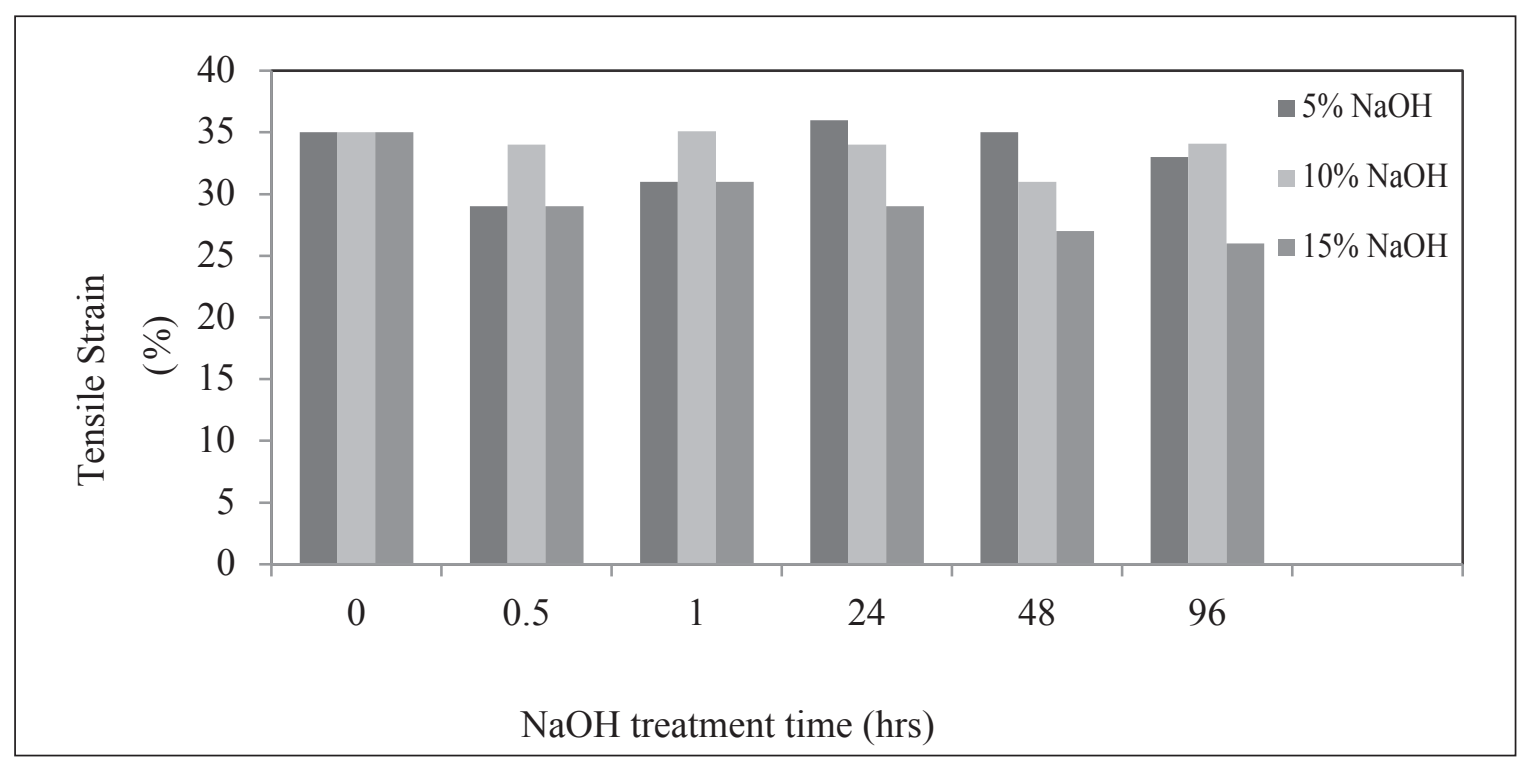

Fig. 3. Tensile strain of $5 \%, 10 \%, 15 \% \mathrm{NaOH}$ treated cane fiber at different times 


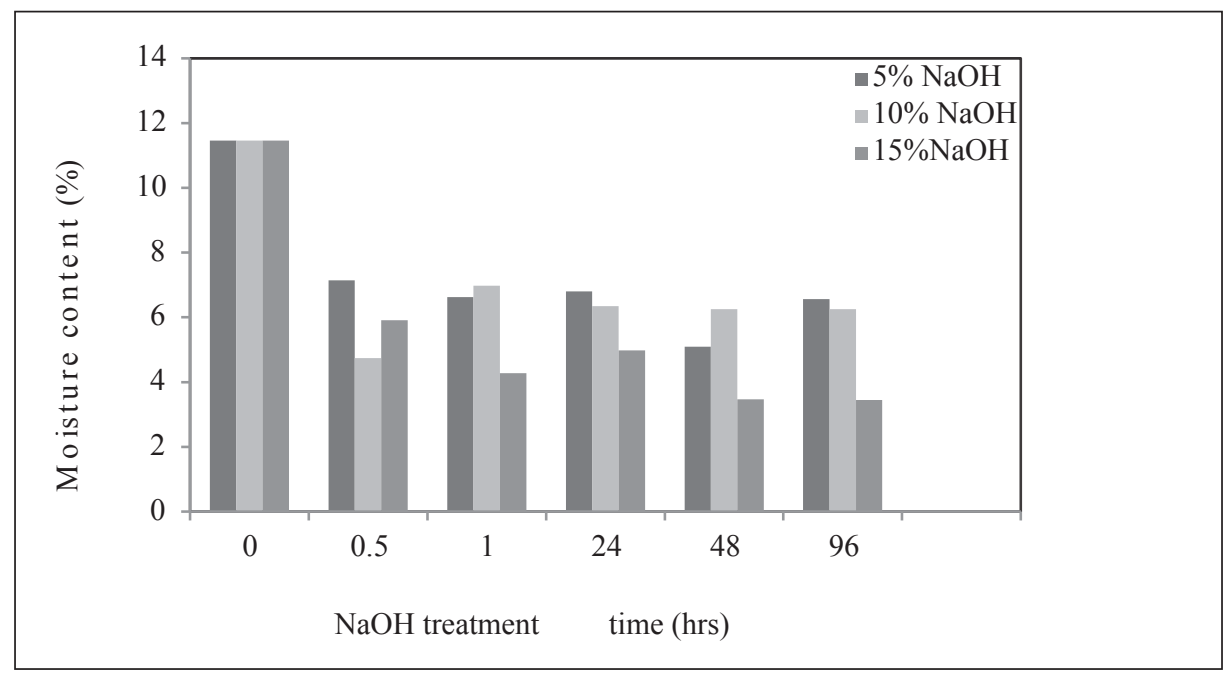

Fig. 4. moisture content (\%) for $5 \%, 10 \%, 15 \% \mathrm{NaOH}$ treated cane fibers at different times

treated fiber at 48 hours is lower than 24 hours. The moisture content is lower at 24 hours for $15 \%$ treated fibers and at 48 hours for $5 \%$ and $15 \%$ treated fibers. The tensile strain is also lower for $15 \% \mathrm{NaOH}$ treated fibers for 24 hours treatment. So, the optimum condition is $15 \% \mathrm{NaOH}$ treated fiber at 24 hours.

\section{Mechanical properties of composite}

Tensile strength

Fig. 5 shows that the ultimate tensile strength is higher for without gap raw fiber orientation of composites (horizontal

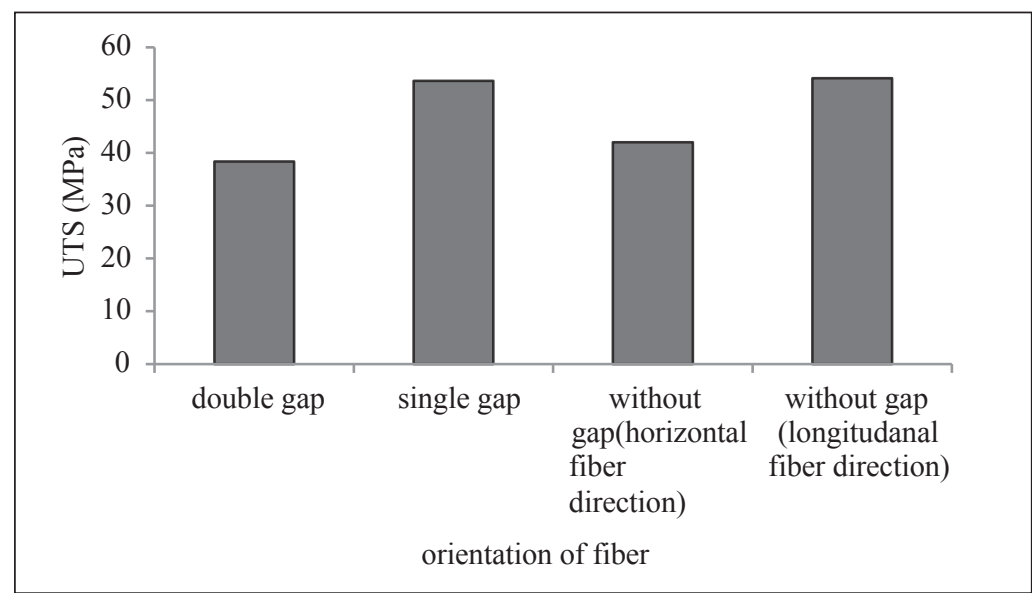

Fig. 5. Ultimate tensile strength of composite for different raw fiber orientation 
fiber direction) than the double gap whereas the single gap and without gap raw fiber orientation of composites (transverse fiber direction) are approximately equal with each other.

Fig. 6 shows that the ultimate tensile strength of the composite for without gap orientation is higher for $15 \%$ $\mathrm{NaOH} 24$ hour treated fiber than the raw fiber.Since raw fiber contains grease and gummy substances interfacial bond of the polymer with the raw fiber is weaker. With alkali treatment the grease and gummy substances are efficiently removed. Lignin and hemi cellulose get hydrolyzed on alkali treatment and thus removed. The carboxyl group and the size of the pores on the fibers is considerably increased from the alkali treatment, i.e. the swelling capacity of the fiber is increased which helps to give better interfacial bonding between the fiber and the matrix. That is why we get better UTS for treated fiber.

Fig. 7 shows that the ultimate tensile strength of the composite increases with the increase of $\mathrm{wt} \%$ of fiber from 20.2 (wt $\%$ of double gap oriented raw fiber composite) to

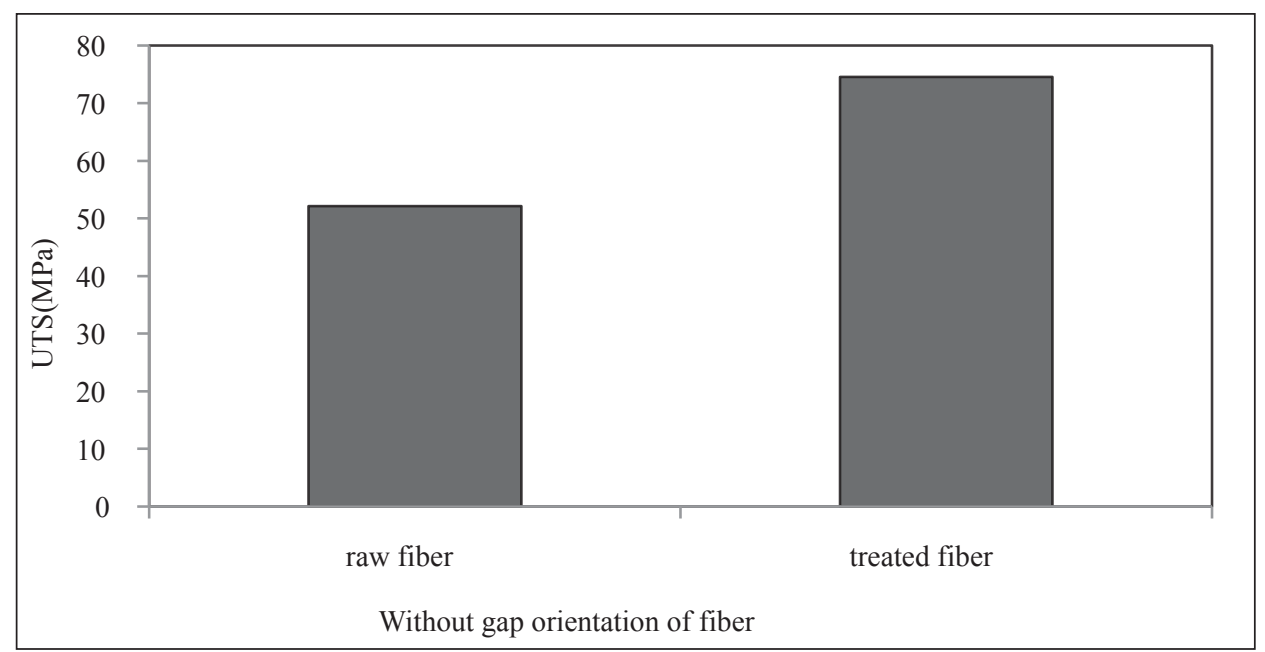

Fig. 6. Ultimate tensile strength of composite for without gap orientation of raw and treated fiber

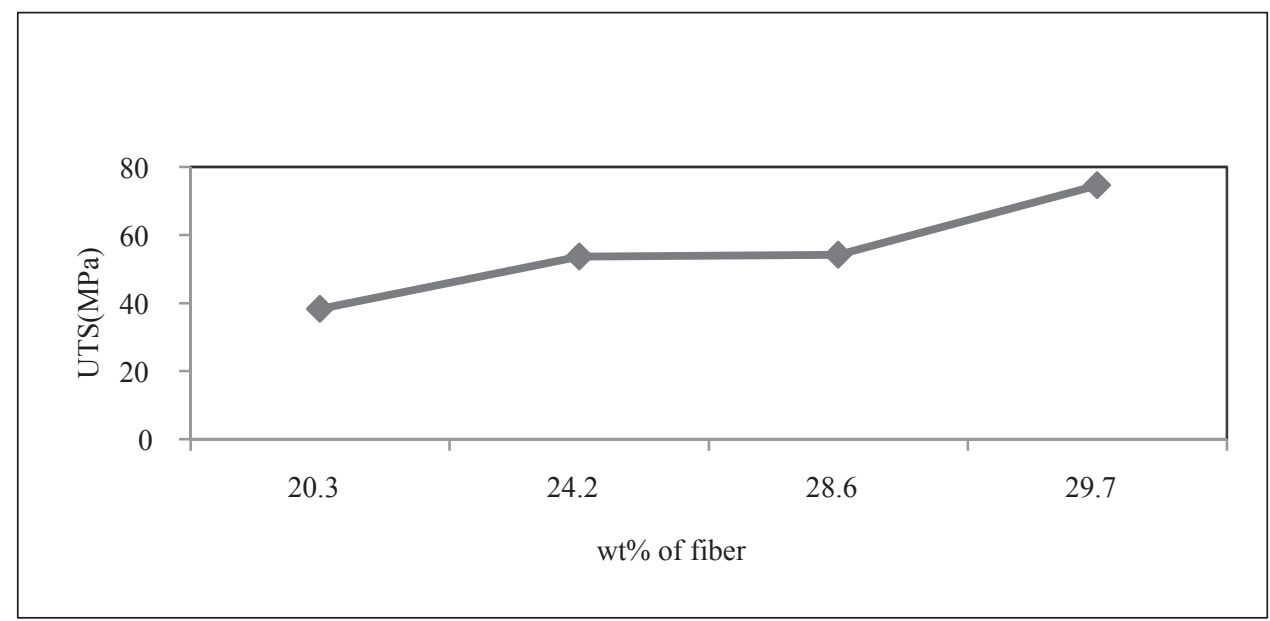

Fig. 7. Ultimate tensile strength of the composite with respect to wt\% of fiber 
24.2 (wt\% of single gap oriented raw fiber composite) and remain apparently constant to 28.6 (wt $\%$ of without gap oriented raw fiber composite). But the ultimate tensile strength reaches highest for 29.7 (wt $\%$ of without gap oriented treated fiber composite).

Fig. 8 shows that the ultimate tensile strength of only resin is lower than the composites of raw and treated fiber for without gap orientation of fiber. These happen because the fiber increase the strength of the composte.

\section{Tensile strain}

Fig. 9 shows that tensile strain (\%) is lower for double gap oriented raw fiber composite and higher for without gap oriented raw fiber composite. Because for without gap orientation the fibers support the load better than the composite with double gap orientation of the fiber.

Fig. 10 shows that tensile strain (\%) is higher for raw fiber reinforced without gap oriented composite and lower for treated fiber reinforced without gap oriented composite. Because the treated fiber reinforced without gap oriented composites adhere with the matrix resin better than the raw fiber reinforced without gap oriented composite.

Fig. 11 shows that tensile strain (\%) for composites increases with the increase of $w t \%$ of raw fiber but decreases for the treated fiber reinforced without gap oriented composite.

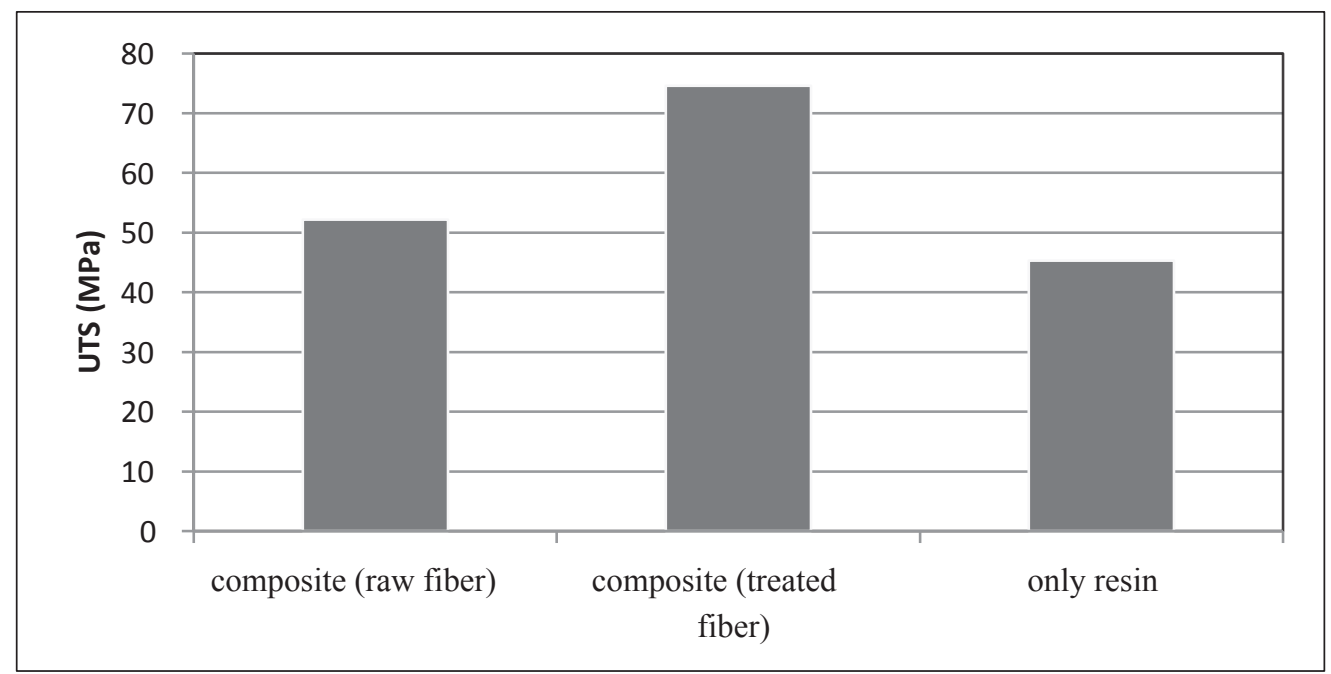

Fig. 8. Ultimate tensile strength with respect to composites of without gap orientation and only resin

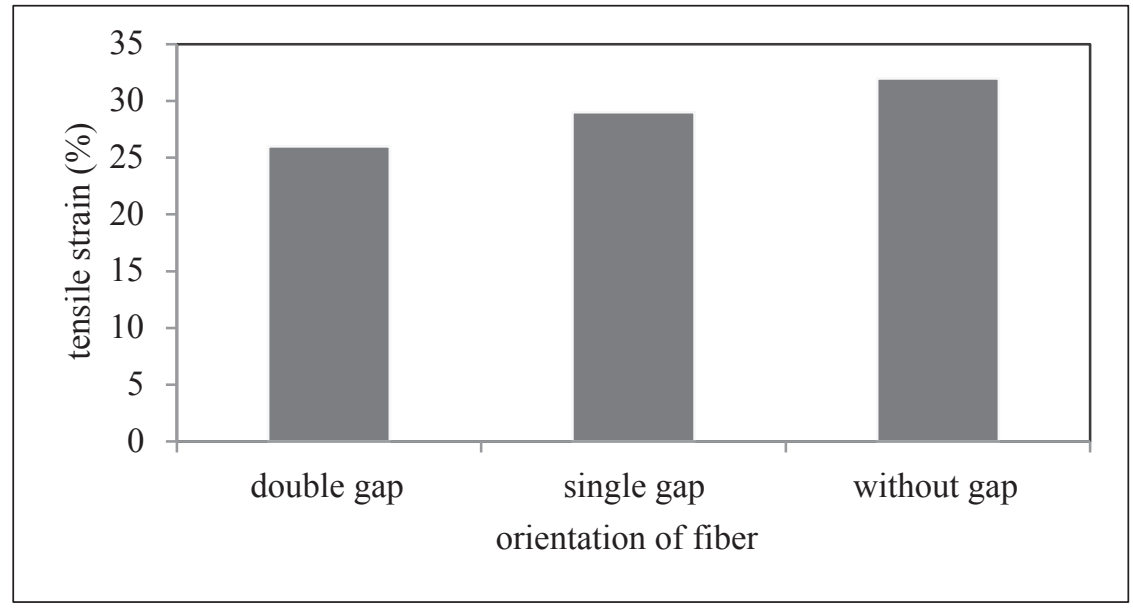

Fig. 9. Tensile strain (\%) of composite for different orientations of raw fiber 
Fig. 12 shows that the tensile strain is lower for only resin compared to composites of raw and treated fiber reinforced composites of without gap orientation of fibers. increases with the increase of wt $\%$ of fiber. Tensile strain is lower for the treated fiber reinforced composite than the raw fiber reinforced composite. Tensile strain increases with the increase of $\mathrm{wt} \%$ of raw fiber reinforced

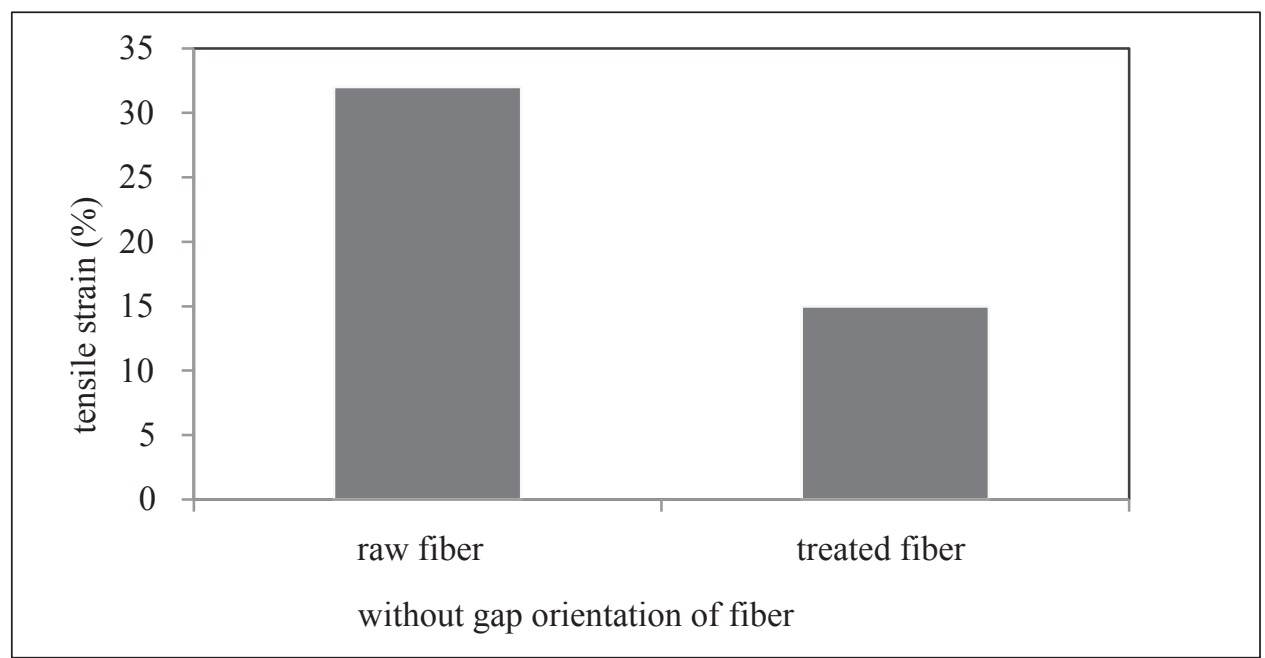

Fig. 10. Tensile strain $(\%)$ of composite for without gap orientation of raw and treated fiber

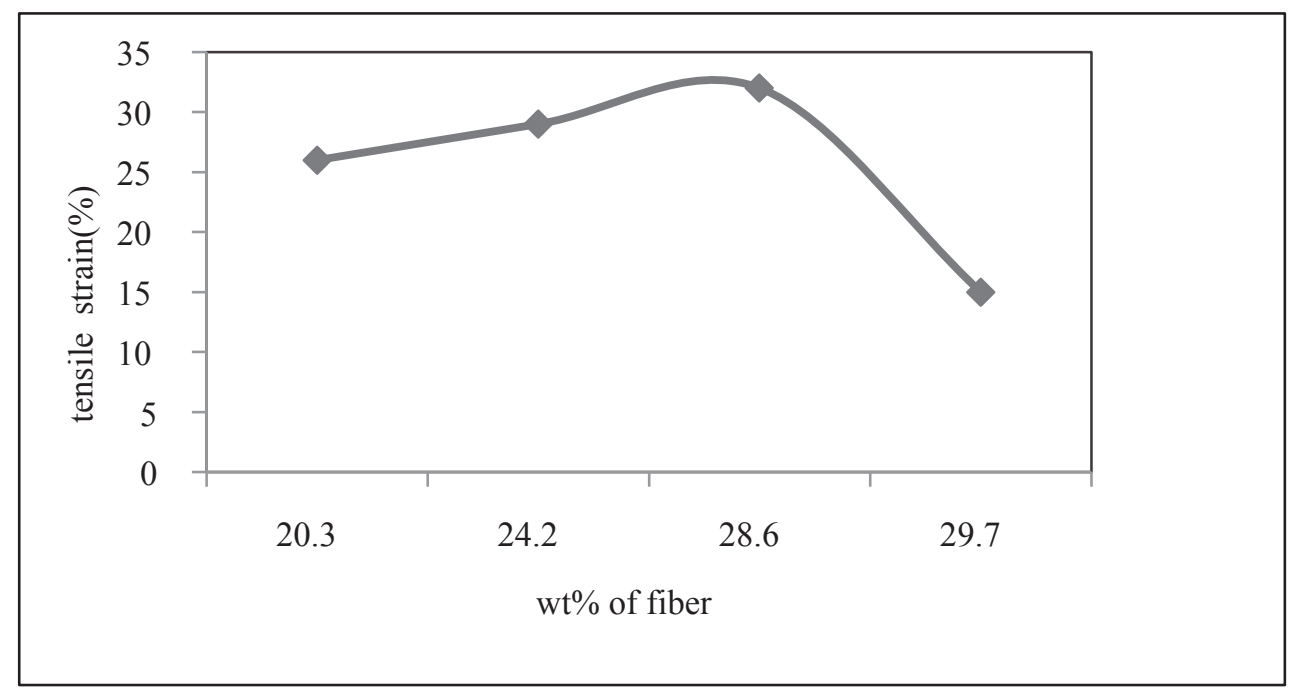

Fig. 11. Tensile strain (\%) of composites with respect to $w t \%$ of fiber

\section{Conclusion}

On the basis of physical and mechanical properties of the composite the optimum condition of fiber treatment was $15 \%$ $\mathrm{NaOH}$ treated fibers at 24 hours. UTS value, $74.58 \mathrm{MPa}$ was higher for $15 \% \mathrm{NaOH}$ treated fiber at 24 hours for reinforced composite than the raw fiber reinforced composites.UTS composite but decreases with the increase of $\mathrm{wt} \%$ of treated fiber reinforced composite.Moisture content decreses with the increase of $\mathrm{NaOH}$ concentration and time. Water absorption is lower for treated fiber reinforced composite than the raw fiber reinfoced composite. 


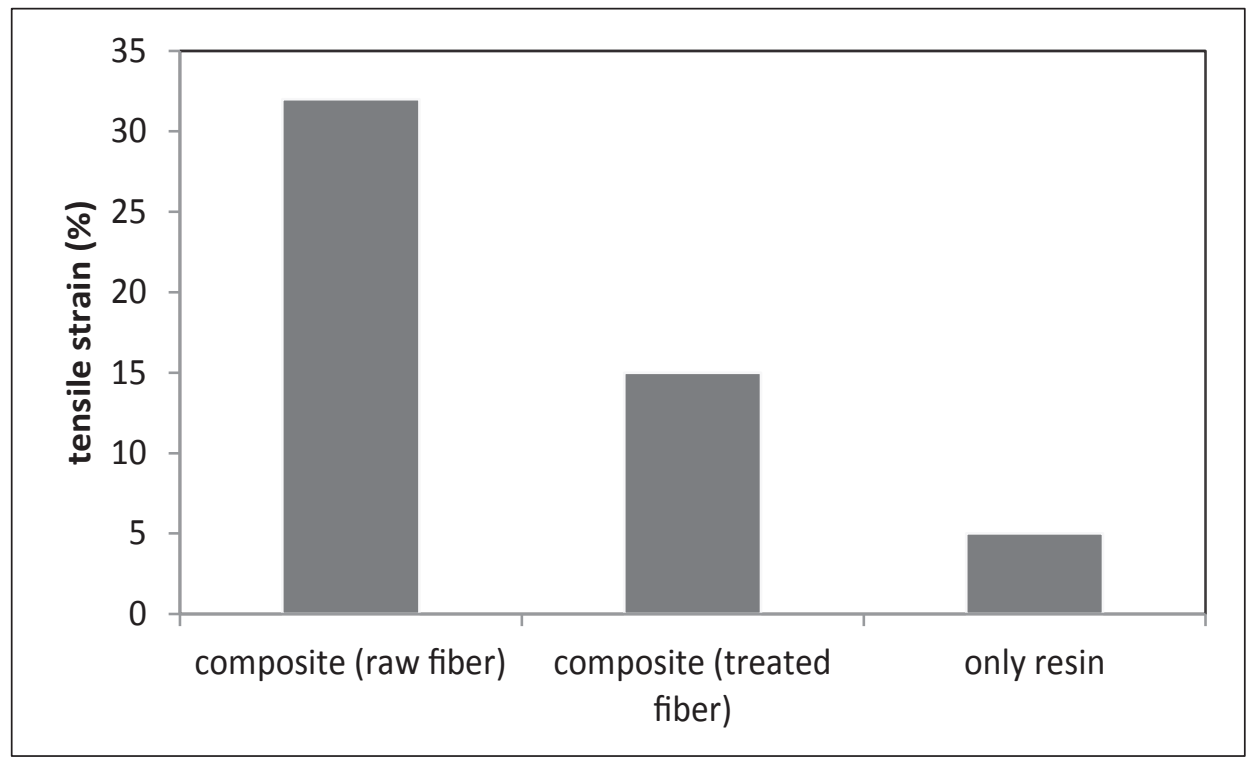

Cane fiber reinforced polyester resin composites

\section{Acknowledgement}

The authors like to thank BCSIR authorities for giving permission and kind cooperation to precede this research work. The authors are also grateful to Dr. M. A. Gafur, PSO, PP \& PDC and BCSIR for providing some of the testing facilities to carry out this research.

\section{References}

Albert F (1972), Hill Economic Botany, TMH Ed., $9^{\text {th }}$ Reprint-1990, pp 18-51.

Akter R, Sultana R, Alam M. Z, Qudir MR, Begum MHA and Gafur MA (2013), Fabrication and Characterization of Woven Natural Fiber Reinforced Unsaturated Polyester Resin Composites 13: 2.

Callister JWD (2000), Materials Science and Engineering -An Introduction John Wiley \& Sons, Inc. New York, 473-547.

Hattum FWJ, Regel F and Labordus M (2011), Cost reduction in manufacturing of aerospace composites, Plast. Rubber Compos. 40: 93-99.
Jawaid M, Khalil HPSA, Khanam PN and Bakar A A (2011), Hybrid composites made from oil palm empty fruit bunches/jute fibers: water absorption, thickness swelling and density behavior, J. Polym. Env. 19(1): 106-109.

Joseph S and Thomas S (2008), Electrical properties of banana fiber - reinforced phenol formaldehyde composites, J. Appl. Sci. 109(1): 256-263.

Kafi A, Abedin MZ, Beg M D H, Pickering K L and Khan M A (2006), Study on the mechanical properties of jute/glass fiber-reinforced unsaturated polyester hybrid composites: Effect of surface modification by Ultraviolet radiation, J. Reinforc. Plast. Compos. 25: $575-588$.

Khan RA, Khan MA, Sultana S, Khan MN, Shubra QTH and Noor FG (2010), Mechanical, Degradation and interfacial properties of synthetic degradable fiber reinforced polypropylene composites, J. Reinforce. Plast. Compos. 29: 466-476. DOI:org/10. $1177 / 0731684408100699$

Mathur VK (2006), Composite materials from local resources, Journal of Construction and Building Materials 20(7): 470-477. 
Nayak SK, Mohanty S and Samal SK (2009), Influence of short bamboo/ glass fiber on the thermal, dynamic mechanical and rheological properties of polypropylene hybrid composites, Materials Science and Engineering 523(1-2): 32-38.

Richardson T (1987), Composite: A design guide, Industrial press.
William D and Callister Jr (2000), Materials Science and Engineering -An Introduction, John Wiley \& Sons, Inc. New York, pp 473-547.

Wiley J and Sons (1998), Journal of Applied Polymer Science 69: 329-338. 